\title{
The Association between Particulate Matter 10 and Severity of Chronic Obstructive Pulmonary Disease, Northern Thailand
}

\author{
P. Pramuansup, T. Apidechkul, N. Pasukphun, and M. Wongkarnka
}

\begin{abstract}
The purpose of this study was to determine the association between particulate matter with $\leq 10 \mu / \mathrm{m}^{3}\left(\mathbf{P M}_{10}\right)$ and the severity of Chronic Obstructive Pulmonary Disease (COPD). A retrospective cohort study design was conducted and collected data by using completed and tested questionnaires. Data were collected from the medical records among the COPD cases from local hospitals in Chiang Rai Province, Thailand. The $\mathbf{P M}_{10}$ was calculated based on two settings of $\mathbf{P M}_{10}$ monitoring system in Chiang Rai Province. The severity of COPD was measured by the Modified Medical Research Council Dyspnea Score (mMRC) method. Logistic regression was applied to test the association between independent and dependent variables. The levels of statistical significance were 0.10 and 0.05 in univariate and multivariate models respectively Results; the different $\mathbf{P M}_{10}$ exposing level was found in the group for exposure to $\mathrm{PM}_{10}(\mathbf{p}<0.10)$ in dry season. Those people who exposed $\mathrm{PM}_{10}$ had a greater in severity of COPD with 5.85 times when compare to un-exposed group $(\mathrm{OR}=5.85$, 95\% CI: 4.12-8.30). Increasing of $\mathrm{PM}_{10}$ level is directly associated with the severity of the COPD, then the increasing of people awareness to avoid and protect from the $\mathbf{P M}_{10}$ are necessary for a better of quality of life among the COPD.
\end{abstract}

Index Terms-COPD, $\mathrm{PM}_{10}$, severity of COPD.

\section{INTRODUCTION}

Chronic obstructive pulmonary disease (COPD) is a common disease and characterized by airflow obstruction. In the population-based studies, COPD affects $5.0-19.0 \%$ of adult population $\geq 40$ years old [1]. It was known that almost $90.0 \%$ of COPD deaths occurred in the low and middle-income countries [2]. COPD is also predominantly caused by smoking. However, other factors, particularly occupational exposures, air pollution are recognized as significant contributors to the development and progression of COPD. According to the latest WHO estimates, currently 64 million people have COPD and 3 million people died from COPD in each year [3].

WHO predicted the COPD will become the third leading cause of death worldwide by 2030 [3]. In Asia-Pacific Countries, the total number of moderate to severe COPD cases among 12 countries of this region was 56.6 million with an overall prevalence proportion of $6.3 \%$. The COPD prevalence proportions among the countries range from $3.5 \%$ (Hong Kong and Singapore) to 6.7\% (Vietnam) and 5.0\% in

Manuscript received December 15, 2012; revised February 15, 2013.

The authors are with the School of Health Science, Mae Fah Luang University, Chiang Rai 57100, Thailand (e-mail: peeyamay22@hotmail.com, tk2516ms@hotmail.com,nittapsp@yahoo.com,wongkarn@yahoo.com).
Thailand [4]. The proportion of death and ill which defined the causes of COPD found from $4.0 \%$ in New Zealand to more than $40.0 \%$ in Sri Lanka and Thailand [5].

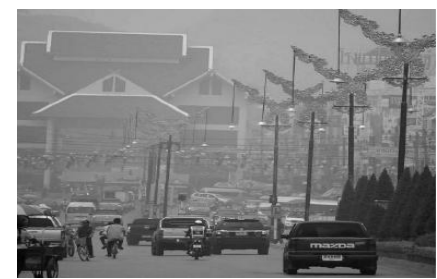

Fig. 1. Air pollution in Mae Sai District, Chiang Rai Province, Thailand, March 2012

All the pollutants, inhalable particulate matter less than 10 micrometer size $\left(\mathrm{PM}_{10}\right)$ shows the association with adverse respiratory health effects. Acute exacerbations of COPD have been associated with short-term exposure to air pollution [6]. Abbey and others [7] found the positive association between $\mathrm{PM}_{10}$ and development of symptoms of COPD productive cough and increased severity of airway obstructive disease, asthma, and stronger than who exposed occupationally to dust and fumes.

During forest fires, northern Thailand and parts of neighboring Myanmar had been covered in layers of smoke, hundreds of kilometers away from the actual fires caused by the burning of forest and agricultural waste. The increasing of small level of smoking could affect to a large proportion of human respiratory system. In Chiang Rai Province found that the number of COPD cases have trended to increase every year, The prevalent proportion of COPD in 2006 to 2008 were 368.32 , 405.45 and 423.50 by 100,000 population [8].

Chiang Rai Province was ranked as the highest $\mathrm{PM}_{10}$ concentrations in Thailand in the year 2009-2010 which had been reported that higher than the standard level. It was indicated that very dangerous for human health particularly in the people who had the medical conditions which related to the respiratory system. In generally, the standard level is 120 micrograms per cubic meter [9]. Since, the little studies on the effect of $\mathrm{PM}_{10}$ and severity of COPD in Thailand particularly in the severe areas as northern Thailand. Then this study was aimed to determine the association between the $\mathrm{PM}_{10}$ level and the severity of COPD in Chiang Rai Province, Thailand.

\section{MATERIALS AND METHODS}

\section{A. Study Design and Study Settings}

The study was a retrospective cohort study design. The 
study sites were 5 districts in Chiang Rai Province, Thailand. The subjects were people who recently diagnosed of COPD from 5 hospitals: Mae Chan, Mae Sai, Payamengrai, Chiang Saen, and Somdet Prayannasungworn Hospitals.

The exposure and un-exposure groups were the same individual. The subjects were measured on March-May 2012 (highest peak $\mathrm{PM}_{10}$ period) as exposure group, meanwhile, in the same individual had been re-measured as the un-exposed on August-October 2011 ( lowest peak PM $_{10}$ period). Then in this study, both of exposure and un-exposure was the same person.

\section{B. Study Population}

The study population was Thai people who had diagnosed with COPD and lived in Chiang Rai Province, Thailand.

\section{The Study Sample and Recruitment}

The samples were patients who recently diagnosed of COPD from 5 local hospitals. The samples size was calculated to arrive at a minimum sample size of 304 cases. The simple random sampling technique was used for selecting the subjects after met the list of COPD cases from hospitals. After providing the information by verbal to the subjects about the objective and process of the study, then the informed consent had been obtained before interview. Inclusion criteria: a) COPD subjects had diagnosed for COPD and visited at the COPD clinics, Chiang Rai Province, b) with the complete medical records. Exclusion Criteria: a) COPD cases who could not speak Thai, b) who refused to participate.

\section{Research Instruments}

The research instruments were the constructed questionnaires with tested for reliability and validity before used. All questions had been tested in the pilot phase and developed before implementing. The questionnaire had been divided into 4 parts. The first part was composed of the questions about general information, socio-economic characteristics. The second part was composed of exposing of the varies of the smoke. The third part was composed of medical history. The last part was composed of environment characteristics. The $\mathrm{PM}_{10}$ concentrations data were collected from secondary information which source from The Pollution Control Department, Ministry of Natural Resources and Environment, Thailand.

\section{E. Data Collection}

All subjects had been asked by the questionnaires in the private and confidential room. Some information had been collected from the medical records. The data collection process was being done during March1, 2012 - May31, 2012. The questions which measured on the severity of COPD were assessed twice: the first time on the low $\mathrm{PM}_{10}$ period (August-October 2011), and the second time the high $\mathrm{PM}_{10}$ period (March-May 2012).

The information of $\mathrm{PM}_{10}$ had been obtained from the Department of Air Pollution Control, Thailand for the year of 2011 - 2012. There were two sites of the $\mathrm{PM}_{10}$ monitoring system were available for obtaining the $\mathrm{PM}_{10}$ information during August-October 2011 and March to May 2012.

\section{F. Statistical Methods}

Descriptive statistics included mean, median, percentile and standard deviation were used to explain the general characteristics of the samples.

Inferential statistics were selected the unconditional logistic regression model for finding the association between the severity of chronic obstructive pulmonary disease and $\mathrm{PM}_{10}$ concentrations. The statistical association for multivariate was considered significance at $\alpha=0.05$.

\section{RESULTS}

TABLE I: TwENTY-Four HOURS AVERAGE PM ${ }_{10}$ CONCENTRATIONS IN CHIANG RAI PROvinCE, THAILAND, 2011-2012.

\begin{tabular}{lcc}
\hline \hline \multirow{2}{*}{ Months } & \multicolumn{2}{c}{ PM $_{\mathbf{1 0}}$ concentrations } \\
\cline { 2 - 3 } & Range $\left(\mu \mathrm{g} / \mathrm{m}^{3}\right)$ & Mean(SD) \\
\hline August 2011 & $14.50-33.70$ & $20.37(12.66)$ \\
September 2011 & $13.90-33.10$ & $22.92(1.06)$ \\
October 2011 & $20.40-47.40$ & $31.15(2.33)$ \\
March 2012 & $48.13-239.38$ & $173.99(73.15)$ \\
April 2012 & $24.33-122.79$ & $69.41(27.70)$ \\
May 2012 & $14.42-58.46$ & $36.47(12.40)$ \\
\hline \hline
\end{tabular}

TABLE II: GENERAL CHARACTERISTICS OF SUBJECTS

\begin{tabular}{|c|c|c|}
\hline Characteristics & n & $\%$ \\
\hline Total & 304 & 100.0 \\
\hline \multicolumn{3}{|l|}{ Sex } \\
\hline Male & 144 & 47.4 \\
\hline Female & 160 & 52.6 \\
\hline \multicolumn{3}{|l|}{ Age (years old) } \\
\hline $40-50$ & 14 & 46 \\
\hline $51-60$ & 40 & 13.2 \\
\hline $61-70$ & 104 & 34.3 \\
\hline $71-80$ & 113 & 37.3 \\
\hline$>80$ & 33 & 10.6 \\
\hline \multicolumn{3}{|l|}{ Marital status } \\
\hline Single & 2 & 0.7 \\
\hline Married & 210 & 69.1 \\
\hline Widowed & 1 & 0.3 \\
\hline Divorced & 91 & 29.9 \\
\hline \multicolumn{3}{|l|}{ Religion } \\
\hline Buddhism & 294 & 96.7 \\
\hline Others & 10 & 3.3 \\
\hline \multicolumn{3}{|l|}{ Income (Baht/month) } \\
\hline$<5,000$ & 249 & 81.9 \\
\hline $5,001-10,000$ & 49 & 16.1 \\
\hline $10,001-15,000$ & 5 & 1.6 \\
\hline$\geq 15,001$ & 1 & 0.4 \\
\hline
\end{tabular}

Table I shows the $\mathrm{PM}_{10}$ concentrations in Chiang Rai Province, Thailand in the year 2011-2012. The highest $\mathrm{PM}_{10}$ level was $239.38 \mu \mathrm{g} / \mathrm{m}^{3}$ on March 2012, whereas the lowest level was $13.90 \mu \mathrm{g} / \mathrm{m}^{3}$ on September 2011. The highest mean of $\mathrm{PM}_{10}$ was 173.99 with SD $73.15 \mu \mathrm{g} / \mathrm{m}^{3}$ on March 2012. The average level of $\mathrm{PM}_{10}$ during the exposure period (March-May 2012) had a higher than the un-exposure period (August-October 2011). March and April had a higher standard level of $\mathrm{PM}_{10}$ which indicated $120 \mu \mathrm{g} / \mathrm{m}^{3}$.

The general characteristics of subjects were shown in Table II. It was found that $52.6 \%$ were female, $37.3 \%$ aged $71-80$ years old, $81.9 \%$ had an income $\leq 5,000$ baht/month, and $63.1 \%$ were retired, $69.1 \%$ were married, and $96.7 \%$ Buddhism.

Table III shows the risk behaviors among the subjects, $85.2 \%$ smoked, $67.4 \%$ used beedi, $72.7 \%$ exposed passive smoke from their family, $85.2 \%$ had been diagnosed COPD 
for $1-5$ years, $80.8 \%$ had got influenza vaccine. $39.1 \%$ had co-morbidities with hypertension, and $61.2 \%$ had acute exacerbation in winter season.

After controlling the possible confounder factors in the unconditional logistic regression model, found in Table IV the $\mathrm{PM}_{10}$ was found the statistically significant association with the severity of COPD with 5.85 times comparing between exposure and non-exposure periods. The COPD had a greater to be severity stage on COPD when came to the dry season with 5.85 time compared to raining season $(95 \% \mathrm{CI}=4.12-8.30)$.

TABLE III: RISK BEHAVIORS AND MEDICAL HISTORY

\begin{tabular}{|c|c|c|}
\hline Characteristics & $\mathbf{N}$ & $\%$ \\
\hline \multicolumn{3}{|l|}{ Smoked } \\
\hline No & 35 & 11.6 \\
\hline Yes & 10 & 3.2 \\
\hline Quit & 259 & 85.2 \\
\hline \multicolumn{3}{|l|}{ Types of smoking } \\
\hline None & 34 & 11.2 \\
\hline Beedi & 205 & 67.4 \\
\hline Cigarette & 26 & 8.6 \\
\hline Both & 39 & 12.8 \\
\hline \multicolumn{3}{|l|}{ Passive cigarette } \\
\hline smoking & 221 & 72.7 \\
\hline No & 83 & 27.3 \\
\hline \multicolumn{3}{|l|}{ Yes } \\
\hline \multicolumn{3}{|l|}{$\begin{array}{l}\text { Diagnosis of COPD } \\
\text { (years) }\end{array}$} \\
\hline$\leq 5$ & 259 & 85.2 \\
\hline $6-10$ & 15 & 4.9 \\
\hline $11-15$ & 16 & 5.2 \\
\hline $16-20$ & 4 & 1.3 \\
\hline $21-25$ & 8 & 2.6 \\
\hline$>25$ & 2 & 0.6 \\
\hline \multicolumn{3}{|l|}{$\begin{array}{l}\text { Receiving Influenza } \\
\text { vaccine }\end{array}$} \\
\hline Yes & 246 & 80.8 \\
\hline No & 58 & 19.1 \\
\hline \multicolumn{3}{|l|}{ Co-morbidities } \\
\hline No & 169 & 55.6 \\
\hline DM & 7 & 2.3 \\
\hline HT & 119 & 39.1 \\
\hline DM and HT & 9 & 3.0 \\
\hline \multicolumn{3}{|l|}{ Acute exacerbation } \\
\hline No & 41 & 13.5 \\
\hline Rainy season & 41 & 13.8 \\
\hline Winter season & 186 & 61.2 \\
\hline All & 35 & 11.5 \\
\hline
\end{tabular}

TABLE IV: MULTIVARIATE ANALYSIS OF PM 10 AND SEVERITY OF COPD

\begin{tabular}{ccc}
\hline \hline Factor & OR & 95\% CI \\
\hline $\mathrm{PM}_{10}$ & 5.85 & $4.12-8.30$ \\
\hline \hline
\end{tabular}

\section{DiscUSSION}

The study was retrospective study design therefore we could not collect all of factors completely and classified the severity of COPD clearly. In some hospitals, they did not have the instruments for assessing the severity of COPD, therefore the classification of severity of COPD method were used clinical symptoms from the medical record cards and self-interview instead. Wan and others [4] found that the proportion of COPD hospitalization by sex in Singapore was 94:16 (male to female). This proportion was difference from our study which shown 47:53.

WHO [10] estimated that in the high-income countries,
$73.0 \%$ of COPD mortality was related to smoking, whereas only $40.0 \%$ related to smoking in the low and middle income countries. However, in our study we found the factors influenced with the severity of COPD was active cigarette smoking $88.4 \%$.

Since the outcome of COPD is always occurring when people reach old age, and most of the COPD cases had the co-morbidity. This is might be the factors influencing to the severity of COPD. In our study, we found that many people had co-morbidity either DM or HT. The result also consisting with the study of van Manen and colleagues [11] which reported that over $50.0 \%$ of 1,145 patients with COPD had 1 to 2 co-morbidities, $15.8 \%$ had 3 to 4 co-morbidities, and $6.8 \%$ had 5 or more co-morbid conditions.

Liu and others [12] found the significant association between the prevalence of COPD and exposing to biomass fuel for cooking in rural China. Our study also found that $4.0 \%$ were typically cooked by charcoal, $1.0 \%$ used wood, and $39.0 \%$ used in both.

In our study, we found that most of the COPD patients had been diagnosed 1 to 5 years and had received influenza vaccine in every year. This is a good indicator of accessing health care system for people who need help by vaccination in Thailand. Cao and colleagues [13] found that the COPD patients who required frequent hospitalizations, the prevalence of influenza vaccination were less than $12.0 \%$. However, in this study found $80.8 \%$ got influenza vaccination.

Donaldson and colleagues [14] found that the exacerbations had found in the cold seasons (November to February), of which $42.5 \%$ and $50.6 \%$ than in warm seasons (May to August) of which $31.4 \%$ and $45.4 \%$. This could make a conclusion that the weather is directly related to the exacerbation.

Since 2008, early of March in every year, there is facing a big environmental problem in the northern of Thailand. The air pollution due to the forest fires covered many kilometers in this area. The study found that the concentrations of $\mathrm{PM}_{10}$ on March 2012 were higher than others and found the lowest $\mathrm{PM}_{10}$ concentrations on September 2011. Usanee and others measured the $\mathrm{PM}_{10}$ concentrations in Chiang Mai Province and found $\mathrm{PM}_{10}$ concentrations on March 2005 had a higher than $\mathrm{PM}_{10}$ concentrations on August and September 2004 [15].

This study found the strongly association between $\mathrm{PM}_{10}$ and severity of COPD statistically significant with 5.85 times comparing between exposure and un-exposure periods. However, Chen and colleagues [16] had done the time series study from Brisbane to investigate the association between forest fires $\mathrm{PM}_{10}$ on respiratory hospital admissions. The results had shown that an increasing in respiratory hospital admissions of $19.0 \%$ for forest fire days and of $13.0 \%$ for days without the presence of forest fires smoke. The study of Johnson and others [17] found an increasing of $10 \mu \mathrm{g} / \mathrm{m} 3$ in $\mathrm{PM}_{10}$ was significantly associated with COPD admission (OR 1.21 95\% CI: 1.00-1.47).

\section{ACKNOWLEDGEMENTS}

This study could not be successful without the collaboration of the hospital directors and COPD clinic staff 
from Payamengrai hospital, Somdet Prayannasungworn hospital, Mae Chan hospital, Mae Sai hospital and Chiang Saen hospital.

\section{REFERENCES}

[1] K. F. Rabe, S. Hurd, A. Anzueto, P. J. Barnes, S. A. Buist, P. Calverley,Y. Fukuchi, C. Jenkins, R. R. Roisin, C. V. Weel, and J. Zielinski, "Global strategy for the diagnosis, management, and prevention of chronic obstructive pulmonary disease GOLD executive summary," Am J Respir Crit Care Med, vol. 6, pp. 532-555, August 2007.

[2] WHO. (November 2011). Burden of COPD. [Online]. Available: http://www.who.int/respiratory/copd/burden/en/index.html.

[3] WHO. (November 2011). Chronic respiratory disease. [Online]. Available: http://www.who.int/respiratory/en/

[4] W. C. Tan and T. P. Ng, "COPD in Asia: where East meets West," Chest, vol. 2, pp. 517-527, Feb. 2008.

[5] A. D. Lopez, C. D. Mather, M. Essati, D. T. Jamison, and J. L. Murray, Global burden of disease and risk factors. In Global Burden of Disease and Risk Factors, The World Bank Group, 2006, ch. 4.

[6] F. W. Ko and D. S. Hui, "Air pollution and chronic obstructive pulmonary disease," Respirology, vol. 17, pp. 395-401, April 2012.

[7] D. E. Abbey, B. L. Hwang, R. J. Burchette, T. Vancuren, and P. K. Mills, "Estrimated long-term ambient concentrations of $\mathrm{PM}_{10}$ and development of symptoms in a non-smoking population," Arch Environ Health,vol. 50, pp. 139-152, March-April 1995.

[8] Chiang Rai Provincial Public Health Office. (November 2011). Annual COPD Epidemiology surveillance report 2008. [Online]. Available: http://cro.moph.go.th/cppho/data/.

[9] Pollution Control Department. (January 2012). Air quality index. [Online]. http://www.pcd.go.th/AirQuality/Regional/DefaultThai.cfm.

[10] D. Bellamyand and R. Booker, Chronic Obstructive Pulmonary Disease in Primary Care, $4^{\text {th }}$ ed. Bridgewater, U.K.: Class Publishing, pp. 8, 2011.

[11] J. G. V. Manen, P. J. E. Bindels, C. J. I. Jsermans, J.S. V. D. Zee, B. J. A M. Bottema, and E. Schade, "Prevalence of comorbidity in patients with a chronic airway obstruction and controls over the age of $40, " J$ Clin Epidemiol, vol. 54, pp. 287-293, March 2011.

[12] S. Lui, Y. Zhou, X. Wang, D. Wang, and J. Lu, "Biomass fuels are probable risk factor for chronic obstructive pulmonary disease in rural South China," Thorax, vol. 62, pp. 889-897, May 2007.

[13] Z. Cao, K. C. Ong, and P. Eng, "Frequent hospital readmissions for acute exacerbation of COPD and their associated factor," Respirology, vol. 11, pp. 188-195, March 2006.

[14] G. C. Donald, J. J. Goldring, and J. A. Wedzicha, "Influence of season on exacerbation characteristics in patients with COPD," Chest, vol. 1 pp. 94-10, Jan. 2012.

[15] V. Usanee, K. P. Taneyhill, T. Chewonarin, N. Chumram, A. Vinitketkumnuen, and S. Tansuwanwong, "Exposure to ambient PM2.5 and PM10 and health effects," CMU.J.Nat.Sci., vol. 6, no. 1, pp.1-10, January-June 2007.

[16] L. Chen, K. Verrall, and S. Tong, "Air particulate pollution due to bushfire and respiratory hospital admissions in Brisbane, Australia,' Int. J. Environ. Health Res, vol. 16, pp. 181-191, June 2006.

[17] F. H. Johnston, R. S. Bailie, and L. S. Pilotto, "Ambient biomass smoke and cardio respiratory hospital admissions in Darwin, Australia," BMC Public Health, vol. 7, pp. 240, Sep. 2007.

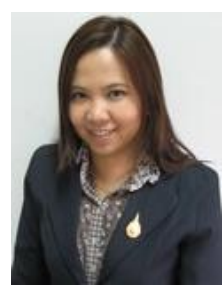

P. Pramuansup was born in Prachinburi Province, Thailand on the $22^{\text {nd }}$ of May 1984. She graduated from the Faculty of Siriraj Medicine at Mahidol University, Bangkok, Thailand with the Bachelor of Applied Thai Traditional Medicine in 2007. She is currently studying for a Master Degree of Science in Public Health (International Program), Mae Fah Luang University, Chiang Rai, Thailand. She is a currently a lecturer in the area of Applied Thai Traditional Medicine, School of Health Science, Mae Fah Luang University, Chiang Rai, Thailand. Her training is on "Ecology and Health", during 21th June-25th July, 2010. University of Hawaii, USA. Supported by Global Health Program, Office of Public Health Studies, University of Hawaii. Ms. Pramuansup is a membership of Applied Thai Traditional Medicine Association of Thailand.

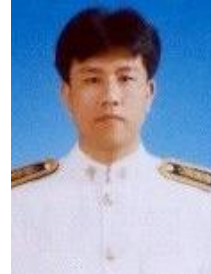

T. Apidechkul was born in Chiang Rai Province, Thailand on the $1^{\text {st }}$ of January. 1973 He graduated from the Faculty of Public Health at Mahidol University in Thailand with the Master of Science in 2000. He received a Doctor of Public Health (International Program) in Epidemiology from Mahidol University, Thailand in 2007. He is currently a lecturer and a chair of Master of Science (Public Health) International Program of School of Health Science, Mae Fah Luang University, Chiang Rai, Thailand. His research publications are: Tawatchai Apidechkul Comparison of quality of life and metal health status among elderly people in rural and suburban areas, Thailand. Southeast Asian J Trop Med Public Health 2011,42;5:1282-92 and Tawatchai Apidechkul. Risk behaviors and bio-markers indicators among elderly population in semi-urban areas, Thailand. Asia Journal of Public Health, April 2012: 3(1); 9-15. Dr. Apidechkul is a membership in the International Epidemiology Association from 1 January 2012 to present and the International Society for Infectious Disease from April 2012 to present. He got the Best Oral Presentation Award, in the 1st International Conference Delivery Management. Thailand 14-16 October 2009

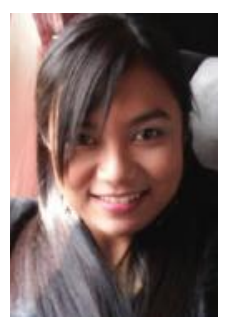

N. Pasukphun was born in Samutprakan Province, Thailand on the $10^{\text {th }}$ of April 1977. She had her Bachelor of Science degree in Environmental Health from the Faculty of Public Health, Burapha University, Thailand in 1999. In that same year she entered the Environmental Technology Division of the school of Energy and Materials in the famous King Mongkut's University of Technology Thonburi, also in Thailand. In 2010, she graduated her Doctor of Philosophy Degree in Environmental Technology from King Mongkut's University of Technology Thonburi, Bangkok, Thailand. She is currently a lecturer of School of Health Science, Mae Fah Luang University, Chiang Rai, Thailand. She had her dissertation "Removal of Organic Substances and Reactive Azo Dye by Anaerobic/Aerobic Biological Activated Carbon - Sequencing Batch Reactor (A/A BAC-SBR)" accepted in 2010 and was subsequently awarded a Doctor of Philosophy degree that same year. Her dissertation was written and published as follows; "Performances and Kinetic characteristics of Unacclimatized and Acclimatized Activated Sludge for Reactive Azo Dyes Removal from Simulated Textile Wastewater", Environmental Engineering and Management Journal, 2006 and "Investigation of Decolorization of Textile Wastewater in an Anaerobic/Aerobic Biological Activated Carbon System (A/A BAC)", Pakistan Journal of Biological Sciences, 2010. Dr. Pasukphun was a membership in Rural Area Development Volunteer Association of Burapha University, Thailand. Currently, she is going to be a part of solid waste management and air pollution research project because it is a major problem of her location and continues her interest on textile wastewater management in context of clean technology including Lanna textile which is regional textile of north of Thailand.

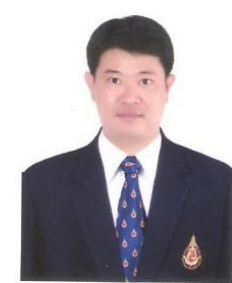

M. Wongkarnka was born in Lopburi Province, Thailand on the $21^{\text {st }}$ of April 1968. He graduated from the Faculty of Science at Mahidol, University, Bangkok, Thailand with the Bachelor of Sanitary Science in 1990. He received a Master of Science in Environmental Technology and Management from Asian Institute of Technology (AIT), Thailand in 1994. Finally, he received his Doctor of Philosophy Degree in Environmental Engineering from Iowa State University, USA in 2005. He is currently a lecturer in the field of environmental engineering, clean technology, water supply and sanitation and family health of School of Health Science, Mae Fah Luang University, Chiang Rai, Thailand. Dr. Wongkarnka is a membership in Environmental Engineering Association of Thailand. 